\title{
Correction to: Identifying coastal and marine priority areas for conservation in the United Arab Emirates
}

\author{
Emna Ben Lamine ${ }^{1,2}$ (D) Daniel Mateos-Molina ${ }^{1,3}$ [D $\cdot$ Marina Antonopoulou' \\ John A. Burt ${ }^{4}$. Himansu Sekhar Das ${ }^{5}$. Salim Javed ${ }^{5}$. Sabir Muzaffar ${ }^{6}$. \\ Sylvaine Giakoumi ${ }^{2,7}$ (D)
}

Published online: 15 April 2021

(c) Springer Nature B.V. 2021

\section{Correction to: Biodiversity and Conservation (2020) 29:2967-2983 https://doi.org/10.1007/s10531-020-02007-4}

The original publication of the article had errors in the reference citation: "Lamine, E.B., Mateos-Molina, D., Antonopoulou, M. et al. Identifying coastal and marine priority areas for conservation in the United Arab Emirates. Biodivers Conserv 29, 2967-2983 (2020). https://doi.org/10.1007/s10531-020-02007-4".

The correct citation is listed below:

"Ben Lamine, E., Mateos-Molina, D., Antonopoulou, M. et al. Identifying coastal and marine priority areas for conservation in the United Arab Emirates. Biodivers Conserv 29, 2967-2983 (2020). https://doi.org/10.1007/s10531-020-02007-4”.

Publisher's Note Springer Nature remains neutral with regard to jurisdictional claims in published maps and institutional affiliations.

The original article can be found online at https://doi.org/10.1007/s10531-020-02007-4.

Daniel Mateos-Molina

dmateos@enwwf.ae

1 Emirates Nature in association with World Wide Fund (Emirates Nature-WWF), The Sustainable City (main entrance), P.O. Box 454891, Dubai, United Arab Emirates

2 Université Côte d'Azur, CNRS, UMR 7035 ECOSEAS, 28 Avenue Valrose, 06108 Nice, France

3 Departamento de Ecología e Hidrología, Universidad de Murcia, Campus de Espinardo, 30100 Murcia, Spain

4 Center for Genomics and Systems Biology, New York University Abu Dhabi, PO Box 129188, Abu Dhabi, United Arab Emirates

5 Environment Agency-Abu Dhabi, Po Box:45553, Abu Dhabi, United Arab Emirates

6 Department of Biology, United Arab Emirates University, Al Ain, P.O. Box 15551, Abu Dhabi, United Arab Emirates

7 Centre for Biodiversity and Conservation Science, School of Biological Sciences, The University of Queensland, Brisbane, QLD, Australia 